\title{
Hot Flushes and Night Sweats in Midlife: Why do Some Women Have Them and Others do Not?
}

\author{
Afrontamentos e Suores Noturnos na Meia-idade: Porque é que \\ Algumas Mulheres os Têm e Outras Não?
}

\author{
Filipa Pimenta*, João Maroco, Catarina Ramos \& Isabel Leal \\ ISPA - Instituto Universitário de Ciências Psicológicas, Sociais e da Vida, Lisboa, Portugal
}

\begin{abstract}
This study investigated what predicts the occurrence of hot flushes (HF) and night sweats (NS). A community sample of 992 women (42-60 years) answered a questionnaire to collect socio-demographic, health and menopause-related, as well as lifestyle information. Depressive mood and stress, as well as HF and NS (in terms of presence, frequency and intensity), were also assessed. Structural equation modelling was used to build a structural model to predict the occurrence of both vasomotor symptoms. Results: Stress predicted NS $(\beta=.154 ; p=.006)$, whereas depressive mood was linked to the occurrence of HF's $(\beta=.149 ; p=.006)$. Being peri-menopausal and post-menopausal, among several other characteristics, were also significant predictors of the occurrence of both HF and NS. This study supports a distinguished influence of stress and depressive mood in NS and HF respectively, probably due to the nature of psychological symptoms. Moreover, significant associations between vasomotor symptoms and socio-demographic, health and menopause-related characteristics, and alcohol were confirmed.

Keywords: Hot flushes, night sweats, stress, depressive mood, structural equation modelling.
\end{abstract}

\begin{abstract}
Resumo
Este estudo investigou os preditores da ocorrência de afrontamentos (Af) e de suores noturnos (SN). Foi utilizada uma amostra comunitária de 992 mulheres (42-60 anos), que respondeu a um questionário para a recolha de informação sociodemográfica, de estado de saúde e menopausa, e sobre o estilo de vida. Os níveis de humor deprimido e estresse, tal como a ocorrência, frequência e intensidade dos Af e SN, foram avaliados. Modelos de equações estruturais foram utilizados para construir o modelo estrutural para predizer a ocorrência de ambos os sintomas vasomotores. Os resultados indicaram que estresse predisse os $\mathrm{SN}(\beta=0,154 ; p=0,006)$, enquanto o humor deprimido associou-se à ocorrência de $\operatorname{Af}(\beta=0,149 ; p=0,006)$. Estar na peri-menopausa ou na pós-menopausa, entre outras características, associou-se igualmente à ocorrência de Af e SN. Este estudo suporta uma influência diferenciada do estresse e do humor deprimido na ocorrência de $\mathrm{SN}$ e Af, respetivamente, provavelmente devido à natureza dos sintomas psicológicos. Adicionalmente confirmou-se uma associação significativa entre os sintomas vasomotores e características sociodemográficas, de saúde, de menopausa e consumo de álcool.

Palavras-chave: afrontamentos, suores noturnos, estresse, humor deprimido, modelos de equações estruturais.
\end{abstract}

Many women, especially in western countries, experience hot flushes during midlife (Stearns et al., 2002) and these tend to increase as women pass from one menopausal status to the following one (Hardy \& Kuh, 2002). However, the prevalence of vasomotor symptoms does not have a

"Mailing address: ISPA - Instituto Universitário de Ciências Psicológicas, Sociais e da Vida, William James Center for Research, Rua Jardim do Tabaco, 34, Lisboa, Portugal 1149-041. E-mail: filipa_pimenta@ispa.pt We kindly acknowledge the Portuguese Fundação para a Ciência e Tecnologia (FCT) for the $\mathrm{PhD}$ grant which allow this research (SFRH/BD/32359/2006). We also thank Raquel Oliveira for proof reading the manuscript. similar distribution between menopausal stages and even in a given stage, in the population of menopausal women (Melby, Lock, \& Kaufert, 2005). In a longitudinal study $(n=2.229)$, the number of women who experience hot flushes $(36 \%)$ is close to the number of women who do not experience hot flushes (29\%), as a result of menopause experience (Gjelsvik, Rosvold, Straand, Dalen, \& Hunskaar, 2011).

The vasomotor symptoms' prevalence varies from $14 \%$ to $51 \%$ in pre-menopause period, from $35 \%$ to $50 \%$ in peri-menopause and from $30 \%$ to $80 \%$ in post-menopause (National Institutes of Health, 2005). These symptoms are frequently identified as the ones that lead to the search for 
medical advice during the menopausal transition (vaginal dryness, decreased libido, joints pain, among others, can also precipitate the search for medical and pharmacological help; Albertazzi, 2007). Also, hot flushes are the most frequent symptoms that are associated with menopause, followed by mood swing, vaginal dryness, sleep problems, night sweats, and memory loss (Asadi, Jouyandeh, \& Nayebzadeh, 2012).

It has been suggested that the origin of vasomotor symptoms is related with higher follicle stimulating hormone (Randolph et al., 2005) and lower estradiol (Blümel et al., 2004). And although these symptoms are likely to occur due to the decline in the estradiol levels, there is still some debate around their mechanisms (Archer et al., 2011; Dennerstein, Dudley, Hopper, Guthrie, \& Burger, 2000; Stearns et al., 2002). While around $70 \%$ of women experience them, only $15-20 \%$ perceive them as problematic due to their particular consequences (such as social embarrassment, distress and physical discomfort; Hunter \& Mann, 2010).

Different variables influence the emergence and/or severity of vasomotor symptoms. They include menopausal (Gold et al., 2000) and health status (Sievert, Obermeyer, \& Price, 2006), the use of hormone therapy (Archer et al., 2011), alcohol intake (Kandiah \& Amend, 2010), smoking (Gjelsvik et al., 2011), physical activity (Kandiah \& Amend, 2010), education level (Gjelsvik et al., 2011), among other.

Psychological factors have also been studied in this field. It has been observed a positive relationship between stress and hot flushes (Gannon, Hansel, \& Goodwin, 1987; Shaw, 1997). Also, a stress reduction intervention can decrease these symptoms' severity (Carmody, Crawford, \& Churchill, 2006).

Depressed mood has also been associated with the presence of vasomotor symptoms (Bromberger et al., 2007; Freeman, Sammel, Lin, \& Nelson, 2006; Hunter \& Liao, 1995; Woods, Mariella, \& Mitchell, 2002), and depression is significantly higher in peri- and post-menopausal women with hot flushes than in their counterparts without this vasomotor symptom (Thurston \& Joffe, 2012). The relation between depression and vasomotor symptoms is bidirectional, according to some studies, that have also found that previous vasomotor symptoms in perimenopausal women were associated with an increased likelihood of depression (Joffe et al., 2002).

Similarly, anxiety is strongly linked to hot flushes, independently of the menopausal status, estradiol levels and smoking (Freeman et al., 2005). However, it is suggested that this association is due to the overlapping of anxiety's somatic symptoms and the hot flushes' physical manifestations, given that these vasomotor symptoms are connected with the somatic dimension of anxiety, but not with the affective one (Lermer et al., 2011).

Because hot flushes may persist in some women, even concomitantly with hormone therapy (Albertazzi, 2007), and because in a minority of women these may persist until the late post-menopause (Huang et al., 2008), it is important to explore which factors are significant predictors of the incidence of vasomotor symptoms. Therefore, the aim of this study is to build a structural model for hot flushes and night sweats' occurrence, using a sample of pre-, peri- and post-menopausal women with and without vasomotor symptoms. Specifically, we will explore if psychological variables (namely, depressive mood, anxiety and stress), health and menopause-related factors, lifestyle and socio-demographic characteristics, can predict the presence of these two vasomotor symptoms. Moreover, it is also our objective to demonstrate if there are significant differences between participants in different menopausal statuses, regarding hot flushes and night sweats' severity, and frequency of anxiety, depressive mood and stress symptoms. Finally, we will analyze if women with vasomotor symptoms differ significantly from women without them in terms of psychological symptoms (anxiety, stress and depressive mood).

\section{Method}

\section{Participants}

A mainly community sample of 992 women in pre-, peri- and post-menopause, recruited in the city of Lisbon, was included in the present study. Ages ranged from 42 to 60 years old.

\section{Procedure}

This cross-sectional study encompasses a community sample, which was mainly recruited through schools and universities in the city of Lisbon. The inclusion criteria in this research were gender (female), literacy and age (between 42 and 60 years old). The American Psychological Association's standards on the ethical treatment of participants were followed. A written informed consent form was delivered to all participants, explaining the aims of the study, emphasizing that the participation in this research was voluntary and that participants could interrupt their collaboration at any time, without any consequences.

\section{Measures}

Vasomotor Symptoms. The instruments included the hot flushes and night sweats' items from the Menopause Symptoms' Severity Inventory, MSSI-38 (Pimenta, Leal, Maroco, \& Ramos, 2012), which evaluates the two symptoms, both in terms of frequency and intensity, in a five-point Likert-type scale (from 0 to 4 ) that ranges from "never" to "daily or almost every day", and from "not intense" to "extreme intensity", respectively. Hot flushes and night sweats' absence was defined as a "never" (0) and a "not intense" (0) answer, regarding the assessment of both frequency and intensity of the symptoms. Women who reported, in the frequency scale, an answer above 0 (that is, 1,2,3 or 4), independent of the intensity level, were classified as having hot flushes, or night sweats. Hence, 
Pimenta, F., Maroco, J., Ramos, C. \& Leal, I. (2015). Hot Flushes and Night Sweats in Midlife: Why do Some Women Have Them and Others do Not?

regarding vasomotor symptoms, participants were divided in two different groups: the ones who had vasomotor symptoms and the ones who did not have these symptoms.

Depression, Anxiety and Stress. To evaluate stress, anxiety and depressive mood, a Portuguese adaptation of the Depression, Anxiety and Stress Scales (Lovibond \& Lovibond, 1995; Pais-Ribeiro, Honrado, \& Leal, 2004) was applied. Each subscale encompasses seven items which are evaluated in a 4-point Lykert-type scale, ranging from 1 ("did not apply to me") to 4 ("it applied to me most of the time"). The instrument presented good psychometric properties.

Menopausal and Health-Related Variables. The menopausal status was defined according to the Stages of Reproductive Aging Workshop's +10 criteria (Harlow et al., 2012). Women in pre-menopause presented an absence of changes in their menstrual cycle. Peri-menopausal participants would report variable cycle length (a difference of more than seven days, than usual) or had skipped two or more cycles, having an amenorrhea interval superior to sixty days. Post-menopausal women had at least a twelvemonth period of amenorrhea.

Besides menopausal status, the use of hormone therapy, herbal/soy products or nothing to manage menopausal symptoms was also asserted. In addition, the search for medical help to manage these symptoms was also controlled.

Health status (both physical and psychological), as well as menopausal status, were self-reported. The participants were inquired about presence of a recent disease and of a psychological problem.

Lifestyle. Alcohol, hot beverages and coffee intake, smoking, physical exercise and body mass index (BMI) were assessed.

Lifestyle habits were explored in terms of presence/absence, amount and/or frequency. Hence, physical exercise was measured in terms of times per week, and during how many minutes the participant exercised; a mean value of weekly frequency and duration was used in the multivariate model. Coffee intake, when present, was assessed in a four-option scale, ranging from "occasionally" to "more than five per day". Alcohol intake, when observed, was measured both in terms of frequency ("daily", "every weekend" or "rarely") and quantity ("until I feel drunk", "moderately" or "less than a glass per occasion"); a mean value of both translates the alcohol consumption variable in the structural model. Finally, for current smokers, smoking was quantified in a 6-point Likert-type scale that ranged from "less than 10 cigarettes per month", until "more than 40 cigarettes per day"; this quantification integrated the structural equation model to assert the influence of smoking on the occurrence of hot flushes and night sweats.

Socio-Demographic Characteristics. Socio-demographic factors such as age, marital status, parity, professional status, educational level and family annual income were explored.

\section{Statistical Analysis}

Missing values were imputated for variables, where its frequency was lower than $10 \%$ of the sample. This was done using the mean interpolation method.

The distribution of the studied variables was explored with SPSS Statistics (v. 19, IBM SPSS Inc, Chicago, IL).

To explore if there were differences between the three menopausal statuses, regarding stress, anxiety and depressive symptoms' frequency, as well as hot flushes and night sweats' severity, a one-way ANOVA followed by post-hoc Tukey's test was performed in order to identify the groups were means were statistically significant different from each other. Variances' homogeneity was confirmed and a Student $t$-test was implemented to evaluate the differences regarding stress, anxiety and depressive mood levels between participants with and without vasomotor symptoms (hot flushes and night sweats) using SPSS Statistics (v. 19, IBM SPSS Inc, Chicago, IL).

Multicollinearity between the independent variables was explored with the variance inflation factor (VIF) given by SPSS Statistics (v. 19, IBM SPSS Inc, Chicago, IL). All variables should present a value below 5 , indicating the absence of collinearity (Maroco, 2010; Weisberg, 1985). Because in the structural model anxiety evidenced a VIF above this value (that is, equal to 66), this variable was excluded from the structural model, since it showed multicollinearity with other independent variables.

To test the structural model for the occurrence of hot flushes and night sweats, a structural equation model was built relating the dependent variable (the two vasomotor symptoms in terms of presence/absence) with the twenty independent variables (namely, age, parity, marital and professional status, income, education, presence of a recent psychological problem or a disease, transition from pre- to peri-menopause and from peri- to post-menopause, use of hormone therapy or herbal/soy products to manage menopause symptomatology, search for medical help to deal with menopause, alcohol and coffee intake, smoking, physical exercise, body mass index, stress and depressive mood). The model was evaluated with SPSS AMOS software (v. 18, IBM SPSS Inc, Chicago, IL). The quality of fit of the structural model was given by chi-square statistics $\left(X^{2} / d f\right)$, comparative fit index (CFI), goodness of fit index (GFI) and root mean square error of approximation (RMSEA), using the reference values indicative of good fit currently practiced in structural equation modelling (Byrne, 2001; Maroco, 2010). A two-step approach was employed to evaluate the structural model. First, the factor's measurement model was evaluated to demonstrate an acceptable fit. Thereafter, the structural model, encompassing the two dependent and the twenty independent variables, was adjusted and the significance of the structural trajectories was evaluated. 


\section{Results}

After receiving the informed consent form and agreeing to participate in the research, a sample of 1,003 Portuguese women completed all instruments adequately (45 were excluded due to insufficient information). Of these, 992 gave sufficient information to be classified in one of the three menopausal statuses and were included in the present study. Table 1 describes the participants.

Table 1

Characterization of the Participants in Relation to Socio-Demographic, Health and Menopause-Related and Lifestyle Variables

\begin{tabular}{lcccccc}
\hline & Pre-menopausal & Peri-menopausal & \multicolumn{2}{c}{ Post-menopausal } \\
\hline Characteristics & $n$ & $\%$ & $n$ & $\%$ & $n$ & $\%$ \\
\hline$n$ & 282 & & 298 & & 412 & \\
Age $(M ; S D)$ & $45.7(3.23)$ & & $47.6(3.79)$ & & $53.9(4.21)$ & \\
Marital status & & & & & & \\
$\quad$ Married or in a relationship & 202 & 71.9 & 218 & 73.2 & 277 & 67.4 \\
$\quad$ Not married or in a relationship & 79 & 28.1 & 80 & 26.8 & 134 & 32.6 \\
Parity & & & & & & \\
$\quad 0$ & 21 & 7.6 & 22 & 7.5 & 42 & 10.4 \\
1 & 83 & 30.0 & 97 & 33.1 & 104 & 25.9 \\
2 & 123 & 44.4 & 136 & 46.4 & 186 & 46.3 \\
3 & 36 & 13.0 & 32 & 10.9 & 49 & 12.2 \\
$>3$ & 14 & 5.1 & 6 & 2.0 & 21 & 5.1
\end{tabular}

Education

Primary school

6.9

28

$9.5 \quad 62$

15.4

Middle school

High school

University degree or higher

Professional status

Active

92.5

Inactive

Family annual income

$$
\begin{aligned}
& \leq 10.000 € \\
& 10.001-20.000 € \\
& 20.001-37.500 € \\
& 37.501-70.000 € \\
& \geq 70.001 €
\end{aligned}
$$

19.5

60

23.9

91

Recent disease

Yes

Recent psychological problem

$$
\text { Yes }
$$

No 
Pimenta, F., Maroco, J., Ramos, C. \& Leal, I. (2015). Hot Flushes and Night Sweats in Midlife: Why do Some Women Have Them and Others do Not?

Search for medical help to deal with menopause

$\begin{array}{lllllll}\text { Yes } & 35 & 13.5 & 136 & 46.7 & 257 & 71.6 \\ \text { No } & 224 & 86.5 & 155 & 53.3 & 102 & 28.4\end{array}$

HT, herbal/soy therapy or Nothing

HT

Herbal/soy therapy

4

0

Nothing

273

1.5

13

$4.5 \quad 49$

13.5

Hot flushes

Yes

31

0

16

$5.5 \quad 48$

13.3

No

11.6

102

36.8

206

55.1

Night sweats

Yes

88.4

175

63.2

168

44.9

No

21.0

115

40.9

200

51.7

Body mass index $\left(\mathrm{kg} / \mathrm{m}^{2}\right)$

$$
\begin{aligned}
& \leq 24,9 \\
& >24,9
\end{aligned}
$$

115

79.0

166

59.1

182

48.3

Physical activity

Yes

162

59.1

157

53.0

205

50.6

No

40.9

139

$47.0 \quad 200$

49.4

Smoking behavior

Current smoker

Current non-smoker

$\begin{array}{cccccc}73 & 26.4 & 87 & 29.7 & 82 & 20.5 \\ 204 & 73.6 & 206 & 70.3 & 318 & 79.5\end{array}$

Alcohol consumption

$$
\text { Yes }
$$

No

49.1

157

53.0

192

47.2

Coffee consumption

Yes

242

50.9

139

47.0

215

52.8

No

38

$86.4 \quad 266$

89.6

344

84.3

Hot beverages intake

Daily

13.6

31

10.4

64

Occasionally or never

28

89.7

10.3

260

92.2

333

87.6

Note. $\mathrm{HT}=$ hormonal therapy.

The measurement model presented an acceptable fit $\left(X^{2} / d f=5.454 ; \mathrm{CFI}=.955 ; \mathrm{GFI}=.946\right.$; $\mathrm{RMSEA}=.070$; $p<.001$; CI $90 \%=] .063 ; .077[)$ and the structural model had a good fit $\left(X^{2} / d f=3.423\right.$; CFI $=.924$; GFI $=.941$; RM$\mathrm{SEA}=.051 ; p=.248$; CI $90 \%=] .048 ; .055[$ ). The structural model is shown in Figure 1.
As shown, the assessed variables account for $20 \%$ and $25 \%$ of the occurrence of the night sweats and of the hot flushes' variability, respectively.

The significant structural weights of each variable as a predictor of hot flushes and night sweats presence are shown in Table 2. 


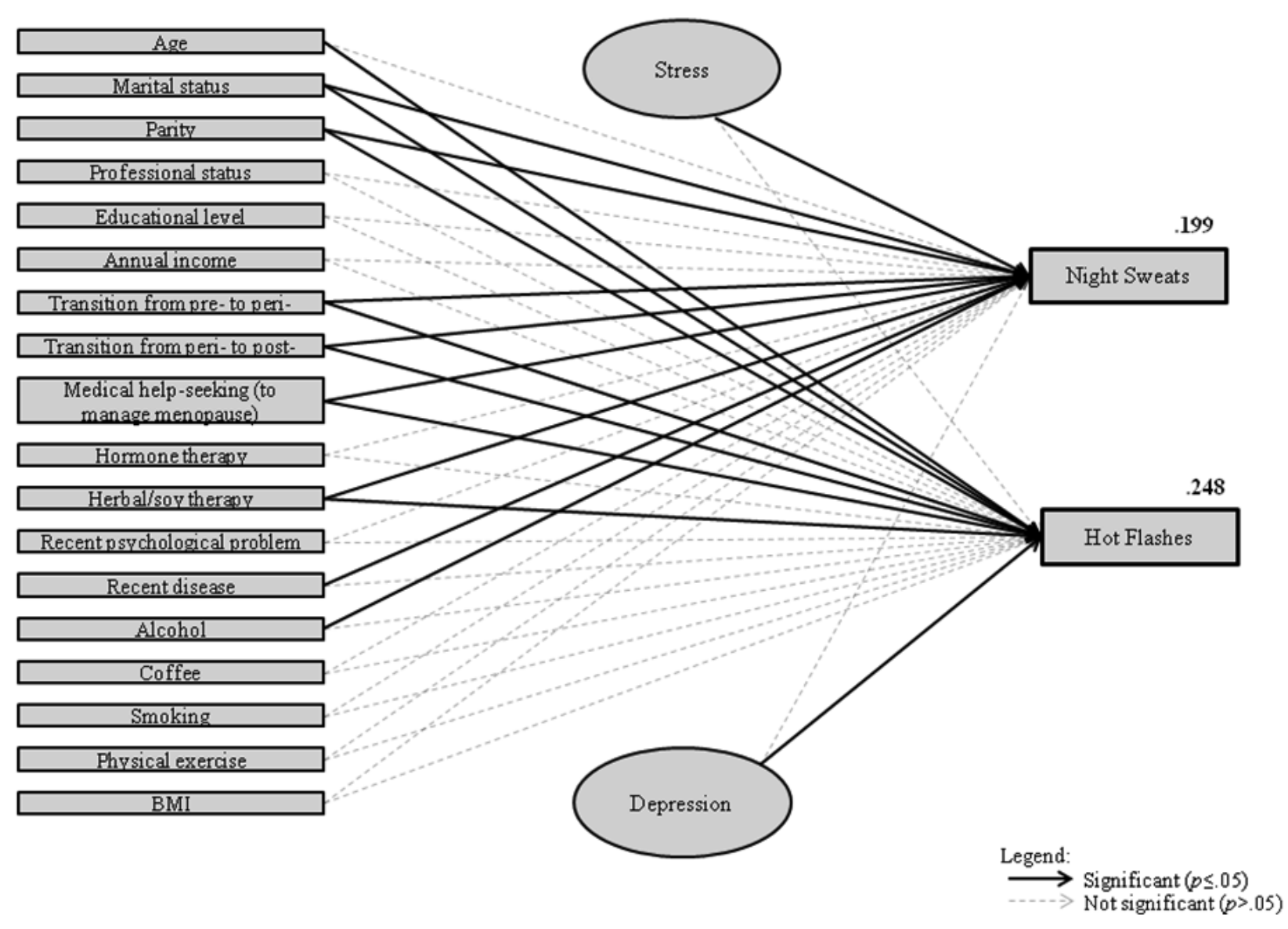

Figure 1. Causal model of hot flushes and night sweats' occurrence.

Table 2

Structural Weights of Independent Variables (socio-demographics, health and menopause-related, lifestyle, stress and depressive mood) in Relation to the Dependent Variables (presence of vasomotor symptoms)

\begin{tabular}{lc} 
Trajectories & $\beta(S E) p$ \\
\hline Hot Flushes $\leftarrow$ Age & $.088(.004) .030$ \\
Night Sweats $\leftarrow$ Age & $.059(.004) .158$ \\
Hot Flushes $\leftarrow$ Marital status & $.111(.033)^{*}$ \\
Night Sweats $\leftarrow$ Marital status & $.118(.034)^{*}$ \\
Hot Flushes $\leftarrow \mathrm{N} .^{o}$ children & $-.075(.013) .011$ \\
Night Sweats $\leftarrow$ N. ${ }^{o}$ children & $-.081(.014) .008$ \\
Hot Flushes $\leftarrow$ Professional status & $-.009(.044) .776$ \\
Night Sweats $\leftarrow$ Professional status & $-.019(.046) .558$ \\
Hot Flushes $\leftarrow$ Educational level & $.007(.010) .844$ \\
Night Sweats $\leftarrow$ Educational level & $.029(.010) .442$ \\
Hot Flushes $\leftarrow$ Household annual income & $.003(.015) .940$ \\
Night Sweats $\leftarrow$ Household annual income & $-.021(.016) .575$ \\
Hot Flushes $\leftarrow$ Transition from pre- to peri-menopause & $.143(.038)^{*}$
\end{tabular}


Pimenta, F., Maroco, J., Ramos, C. \& Leal, I. (2015). Hot Flushes and Night Sweats in Midlife: Why do Some Women Have Them and Others do Not?

Night Sweats $\leftarrow$ Transition from pre- to peri-menopause

$.096(.040) .011$

Hot Flushes $\leftarrow$ Transition from peri- to post-menopause

$.221(.047)^{*}$

Night Sweats $\leftarrow$ Transition from peri- to post-menopause

$.108(.049) .028$

Hot Flushes $\leftarrow$ Medical help seeking (to manage menopause)

$.178(.032) *$

Night Sweats $\leftarrow$ Medical help seeking (to manage menopause)

$.161(.034) *$

Hot Flushes $\leftarrow$ Hormone therapy

$-.046(.058) .131$

Night Sweats $\longleftarrow$ Hormone therapy

$.018(.061) .572$

Hot Flushes $\leftarrow$ Herbal/soy therapy

$.087(.058) .004$

Night Sweats $\leftarrow$ Herbal/soy therapy

$.086(.061) .006$

Hot Flushes $\leftarrow$ Recent psychological problem

-.031(.043).333

Night Sweats $\leftarrow$ Recent psychological problem

-.032(.045).328

Hot Flushes $\leftarrow$ Recent disease

$.053(.038) .074$

Night Sweats $\leftarrow$ Recent disease

$.080(.039) .010$

Hot Flushes $\leftarrow$ Alcohol intake

$.049(.019) .107$

Night Sweats $\leftarrow$ Alcohol intake

$.120(.019) *$

Hot Flushes $\leftarrow$ Coffee intake

$.010(.017) .751$

Night Sweats $\leftarrow$ Coffee intake

$.023(.018) .488$

Hot Flushes $\leftarrow$ Hot beverages intake

-.033(.020).298

Night Sweats $\leftarrow$ Hot beverages intake

$-.044(.021) .180$

Hot Flushes $\leftarrow$ Physical exercise

$-.037(.000) .210$

Night Sweats $\leftarrow$ Physical exercise

-.031(.000).299

Hot Flushes $\leftarrow$ BMI

$.057(.004) .069$

Night Sweats $\leftarrow$ BMI

$.047(.004) .148$

Hot Flushes $\leftarrow$ Smoking

$-.023(.009) .454$

Night Sweats $\longleftarrow$ Smoking

-.021(.009).514

Hot Flushes $\leftarrow$ Stress

$.091(.041) .093$

Night Sweats $\longleftarrow$ Stress

$.154(.043) .006$

Hot Flushes $\leftarrow$ Depressive mood

$.149(.051) .006$

Night Sweats $\leftarrow$ Depressive mood

$.086(.053) .121$

Note. $\beta=$ standardized estimates; $S E=$ standard error. $* p \leq .001$.

Table 3 evidences the mean levels of vasomotor symptoms' severity, and of stress, anxiety and depressive mood symptoms' frequency, as well as, the differences between the three menopausal statuses.

To explore if there are significant differences between women who have, and those who do not have, vasomotor symptoms in relation to depressive mood, anxiety and stress, the two groups were compared. The results are presented in the Table 4.

\section{Discussion}

In this community sample, women with hot flushes and night sweats presented significantly higher levels of stress, anxiety and depressive mood. Regarding the menopausal status, post-menopausal women always presented more severe hot flushes and night sweats compared with their peri-menopausal counterparts. However, these two menopausal statuses did not differ significantly in terms 
Psychology/Psicologia: Reflexão e Crítica, 28(4), 753-763.

Table 3

Mean Scores for Vasomotor and Psychological Variables and Differences between the Three Menopausal Statuses

\begin{tabular}{|c|c|c|c|c|c|c|}
\hline \multirow{2}{*}{$\begin{array}{l}\text { Variables } \\
\text { Hot Flushes severity }\end{array}$} & \multirow{2}{*}{$\begin{array}{c}\text { Pre- } \\
M(S D) \\
.2(.566)\end{array}$} & \multirow{2}{*}{$\begin{array}{c}\text { Peri- } \\
M(S D) \\
.8(1.197)\end{array}$} & \multirow{2}{*}{$\begin{array}{c}\text { Post- } \\
M(S D) \\
1.2(1.366)\end{array}$} & \multicolumn{3}{|c|}{$\begin{array}{c}\text { one-way ANOVA } \\
M D(S E) p\end{array}$} \\
\hline & & & & Pre- & Peri- & $-.591(.097)^{*}$ \\
\hline & & & & Pre- & Post- & $-1.056(.091)^{*}$ \\
\hline & & & & Peri- & Post- & $-.464(.090)^{*}$ \\
\hline \multirow[t]{3}{*}{ Night Sweats severity } & $.3(.677)$ & $.8(1.204)$ & $1.2(1.365)$ & Pre- & Peri- & $-.518(.098)^{*}$ \\
\hline & & & & Pre- & Post- & $-.869(.092)^{*}$ \\
\hline & & & & Peri- & Post- & $-.350(.090)^{*}$ \\
\hline \multirow[t]{3}{*}{ Depressive mood } & $1.3(.478)$ & $1.4(.535)$ & $1.5(.644)$ & Pre- & Peri- & $-.081(.047) .199$ \\
\hline & & & & Pre- & Post- & $-.173(.044)^{*}$ \\
\hline & & & & Peri- & Post- & $-.091(.043) .090$ \\
\hline \multirow[t]{3}{*}{ Stress } & $1.6(.500)$ & $1.7(.559)$ & $1.8(.606)$ & Pre- & Peri- & $-.133(.047) .012$ \\
\hline & & & & Pre- & Post- & $-.168(.044)^{*}$ \\
\hline & & & & Peri- & Post- & $-.035(.043) .694$ \\
\hline \multirow[t]{3}{*}{ Anxiety } & $1.2(.307)$ & $1.4(.467)$ & $1.4(.545)$ & Pre- & Peri- & $-.150(.039)^{*}$ \\
\hline & & & & Pre- & Post- & $-.228(.036)^{*}$ \\
\hline & & & & Peri- & Post- & $-.078(.035) .071$ \\
\hline
\end{tabular}

Note. $M D=$ mean difference; $S E=$ standard error.

${ }^{*} p \leq .001$.

Table 4

Comparison of Women With and Without Hot Flushes (HF) and Night Sweats (NS) Regarding Levels of Stress, Anxiety and Depressive Mood

\begin{tabular}{lcccccc}
\hline \multirow{2}{*}{ Psychol. Variables } & $\begin{array}{c}\text { With HF } \\
M(S D)\end{array}$ & $\begin{array}{c}\text { Without HF } \\
M(S D)\end{array}$ & $\begin{array}{c}t \text {-student } \\
t(d f) p\end{array}$ & $\begin{array}{c}\text { With NS } \\
M(S D)\end{array}$ & $\begin{array}{c}\text { Without NS } \\
M(S D)\end{array}$ & $\begin{array}{c}t \text {-student } \\
t(d f) p\end{array}$ \\
\hline Anxiety & $1.6(.577)$ & $1.2(.332)$ & $-9.249(471.816)^{*}$ & $1.5(.556)$ & $1.2(.336)$ & $-9.429(542.012)^{*}$ \\
Stress & $1.9(.577)$ & $1.6(.517)$ & $-6.357(622.301)^{*}$ & $1.9(.602)$ & $1.6(.504)$ & $-6.837(686.538)^{*}$ \\
Depressive mood & $1.6(.677)$ & $1.3(.464)$ & $-6.851(528.208)^{*}$ & $1.6(.665)$ & $1.3(.469)$ & $-6.246(603.198)^{*}$ \\
\hline
\end{tabular}

${ }^{*} p \leq .001$.

of depressive mood, stress and anxiety. Therefore, given the results of the univariate analysis, the frequency of anxiety, depressive mood and stress symptoms is only statistically different when considering the presence of vasomotor symptoms (instead of taking into account the menopausal status) in peri- and post-menopausal women (although in the first analysis - regarding the presence/ absence of vasomotor symptoms - pre-menopausal women are included, they are a small part of this sample; that is, 31 participants and 57 women in pre-menopause reported hot flushes and night sweats, respectively).
Although there is strong evidence that vasomotor symptoms are one of the few clinical manifestations strongly associated with the hormonal fluctuation observed in the peri-menopause (Deecher \& Dorries, 2007), these symptoms have been reported in some studies by premenopausal women (Freeman et al., 2005). In the present study this was observed: as mentioned before, $12 \%$ and $21 \%$ of women in pre-menopause reported hot flushes and night sweats, respectively.

It could be hypothesized that this translates a limitation on the assessment of the menopausal status - in this study a 
Pimenta, F., Maroco, J., Ramos, C. \& Leal, I. (2015). Hot Flushes and Night Sweats in Midlife: Why do Some Women Have Them and Others do Not?

self-report method based on STRAW+10 criteria (Harlow et al., 2012) was used - which could evidence that, although the menstrual period of these participants did not evidence alterations, minimal hormonal changes (not translated in manifest menstrual alterations) might promote these vasomotor symptoms. Also, it can be thought that socio-cultural factors (such as the identification with menopausal-peers), as well as the perception of age progressing towards an age interpreted as "menopausal", might influence the interpretation of elevated body temperature (for reasons other than hormonal) as vasomotor symptoms. Despite these hypotheses, the assessment of the menopausal status through age and self-assessment of the menstrual history, as done in the present research, has been evidenced as a more accurate way of determining the menopausal status rather than using the presence of particular symptoms (such as vasomotor symptoms) or hormone levels given by laboratory tests (Bastian, Smith, \& Nanda, 2003).

The structural model encompassing socio-demographic, health, menopause-related, lifestyle and psychological variables (stress and depressive mood), demonstrates that there are several factors that can predict the presence of vasomotor symptoms in midlife women. Age progression was a significant variable in relation to the appearance of hot flushes. Also, being married (or in a relationship) and having less children (or no children) predicted the presence of both vasomotor symptoms. In other studies, being divorced was associated with bothersomeness of vasomotor symptoms (Avis, Crawford, \& McKinlay, 1997) and parous women evidenced a higher frequency of vasomotor symptoms (Progetto Menopausa Italia Study Group, 2005).

Menopausal status (namely, being peri- and postmenopausal), as well as medical help sought to manage menopause, significantly predicted the occurrence of both hot flushes and night sweats. This is congruent with researches which evidence that the vasomotor symptoms result from the decrease in endogenous estrogens (Blümel et al., 2004; Randolph et al., 2005), and are the most common reason to search for medical help search to deal with menopause (Albertazzi, 2007; Avis et al., 1997; Guthrie, Dennerstein, Taffe, \& Donnelly, 2003; Whitcomb, Whiteman, Langenberg, Flaws, \& Romani, 2007).

The use of herbal/soy products was significantly associated with both vasomotor symptoms. These results are consistent with other studies (Haimov-Kochman \& Hochner-Celnikier, 2005; Thurston \& Joffe, 2012). A review on herbal products' efficacy for the treatment of menopausal symptoms has concluded that there is no convincing evidence and that the data on these products is doubtful given the poor methodology used in studies that document benefits of the herbal therapies and safety concerns (namely, regarding the use of kava; Huntley \& Ernest, 2003). Therefore, the use of natural products for the treatment of hot flushes and night sweats should receive further attention and be thoroughly researched. However, it is reasonable to think that women without symptoms are less likely to use herbal/soy products. In addition, it can be hypothesized that some women with bothersome symptoms may have opted, or have been suggested to use natural products, in alternative to the hormonal therapy.

The physical health status (specifically, the presence of a recent disease) was also significant in the prediction of night sweats. This outcome supports a previous study where a health status qualified as excellent was linked to a decrease in night sweats, but not in hot flushes (Sievert et al., 2006).

Lifestyle factors can significantly influence the degree of vasomotor symptoms' reporting (Avis et al., 1997). In particular, daily alcohol consumption has been described as a habit that increases the probability of incidence and bothersomeness of night sweats (Sievert et al., 2006). In this study, only alcohol intake predicted one of the vasomotor symptoms. Therefore, higher alcohol intake was linked to the presence of night sweats. This emphasizes a conclusion drawn in prior researches which identify alcohol as a risk factor for vasomotor symptoms (Kandiah \& Amend, 2010; Progetto Menopausa Italia Study Group, 2005; Shaw, 1997; Sievert et al., 2006). Smoking, coffee, physical exercise and BMI were not significant predictors of the occurrence of night sweats or hot flushes, in this sample.

The different influences of the two psychological variables in the vasomotor symptoms, namely stress predicting night sweats (but no hot flushes) and depressive mood predicting hot flushes (and not night sweats) might be related with the nature of the psychological symptoms itself.

Individuals with higher stress levels have been identified as having lower sleep efficiency, higher latency on the first stage of sleep and increased arousal (Drake, Richardson, Roehrs, Scofield, \& Roth, 2004). Another study has reported that vasomotor symptoms are associated with sleep disturbance and poor sleep continuity and quality (Kravitz et al., 2008). Since higher levels of stress predicted the occurrence of night sweats, this relation can be mediated by the sleep disturbance that results from higher levels of stress.

Furthermore, it has been found that in a non-clinical sample of women with varying degrees of depressed mood, in women with higher scores of depressed mood, the negative affect was observed more significant during the morning; additionally, an improvement in depressive mood was evidenced in the evening (Murray, 2007). It is hypothesized that this diurnal nature of the depressed mood might partially explain the connection of depressive mood with hot flushes' occurrence, but not with night sweats. Moreover, it had already been highlighted that menopausal women were more likely to experience hot flushes if they were depressed (Juang, Wang, Lu, Lee, \& Fuh, 2005), stressed, anxious or with negative affect (Thurston \& Joffe, 2012). Furthermore, this study has also demonstrated that women with hot flushes present a significantly higher depressive mood than their counterparts without hot flushes. 
The variables assessed account for $20 \%$ and $25 \%$ of the occurrence of night sweats and hot flushes' variability, respectively. Hence, variables, other than the included in this study, may have an impact in the emergence of vasomotor symptoms. For example, a structural model predicting the severity of both hot flushes and night sweats in a sample of symptomatic women (that is, who evidenced vasomotor symptoms in the previous month) showed that perceived control over vasomotor symptoms was the strongest and most significant predictor of the symptoms' severity; moreover, that structural model explained $67 \%$ and $72 \%$ of the variability of hot flushes and night sweats' severity, respectively (Pimenta, Leal, Maroco, \& Ramos, 2011). And although vasomotor symptoms are strongly associated with hormonal variations (Dennerstein et al., 2000) there might be other non-hormonal variables that account for the presence of vasomotor symptoms in midlife women.

The sample size (992 participants) was adequate for this type of statistical analysis given it was applied a rule of thumb of ten subjects per manifest variable, as is current practice in structural equation modelling (Kline, 2005; Maroco, 2010). Nevertheless, the fact that this research has a cross-sectional design, and that it uses a sample where a significant part of the participants has a college degree, limits the generalization of these results.

In conclusion, this research shows that vasomotor symptoms' occurrence might be predicted by several variables, namely, socio-demographic characteristics (age, marital status and parity), menopausal status, medical help-seeking (to manage menopause), use of herbal/soy therapies, health status, alcohol intake and psychological symptoms (depression and stress). Moreover, the different influences of the two psychological variables in the vasomotor symptoms, namely stress predicting night sweats (but no hot flushes) and depression predicting hot flushes (and not night sweats), might be related with the nature of the psychological symptoms itself. Additionally, it was concluded that participants with hot flushes and night sweats presented significantly higher levels of stress, anxiety and depression.

\section{References}

Albertazzi, P. (2007). Non-estrogenic approaches for the treatment of climacteric symptoms. Climacteric, 10(Suppl. 2), 115-120. doi:10.1080/13697130701440980

Archer, D. F., Sturdee, D. W., Baber, R., de Villiers, T. J., Pines, A., Freedman, R. R., ...Warren, M. (2011). Menopausal hot flushes and night sweats: Where are we now? Climacteric, 14(5), 515-528. doi:10.3109/13697137.2011.608596

Asadi, M., Jouyandeh, Z., \& Nayebzadeh, F. (2012). Prevalence of menopause symptoms among Iranian women. Journal of Family and Reproductive Health, 6(1), 1-3. Retrieved from http://jfrh.tums.ac.ir/index.php/jfrh/article/view/291

Avis, N. E., Crawford, S. L., \& McKinlay, S. M. (1997). Psychosocial, behavioral, and health factors related to menopause symptomatology. Women's Health, 3(2), 103-120.
Bastian, L. A., Smith, C. M., \& Nanda, K. (2003). Is this woman perimenopausal? JAMA, 289(7), 895-902. doi:10.1001/ jama.289.7.895

Blümel, J. E. M., Castelo-Branco, C., Cancelo, M. J., Córdova, A. T., Binfa, L. E., Bonilla, H. G., ...Sarrá, S. C. (2004). Relation between psychological complaints and vasomotor symptoms during climacteric. Maturitas, 49(3), 205-210. doi:10.1016/j. maturitas.2004.01.011

Bromberger, J. T., Matthews, K. A., Schott, L. L., Brockwell, S., Avis, N. E., Kravitz, H. M., ...Randolph, J. F., Jr. (2007). Depressive symptoms during the menopausal transition: The Study of Women's Health Across the Nation (SWAN). Journal of Affective Disorders, 103(1-3), 267-272. doi:10.1016/j. jad.2007.01.034

Byrne, B. M. (2001). Structural equation modeling with AMOS: Basic concepts, applications, and programming. Mahwah, NJ: Lawrence Erlbaum.

Carmody, J., Crawford, S., \& Churchill, L. (2006). A pilot study of mindfulness-based stress reduction for hot flashes. Menopause, 13(5), 760-769. doi:10.1097/01. gme.0000227402.98933.d0

Deecher, D. C., \& Dorries, K. (2007). Understanding the pathophysiology of vasomotor symptoms (hot flushes and night sweats) that occur in perimenopause, menopause, and postmenopause life stages. Archives of Women's Mental Health, 10(6), 247-257. doi:10.1007/s00737-007-0209-5

Dennerstein, L., Dudley, E., Hopper, J., Guthrie, J., \& Burger, H. A. (2000). A prospective population-based study of menopausal symptoms. Obstetrics \& Gynecology, 96(3), 351-358. doi:10.1016/S0029-7844(00)00930-3

Drake, C., Richardson, G., Roehrs, T., Scofield, H., \& Roth, T. (2004). Vulnerability to stress-related sleep disturbance and hyperarousal. Sleep, 27(2), 285-292.

Freeman, E., Sammel, M., Lin, H., Gracia, C., Kapoor, S., \& Ferdousi, T. (2005). The role of anxiety and hormonal changes in menopausal hot flashes. Menopause, 12(3), 258-266. doi:10.1097/01.GME.0000142440.49698.B7

Freeman, E. W., Sammel, M. D., Lin, H., \& Nelson, D. B. (2006). Associations of hormones and menopausal status with depressed mood in women with no history of depression. $A r-$ chives of General Psychiatry, 63(4), 375-382. doi:10.1001/ archpsyc.63.4.375

Gannon, L., Hansel, S., \& Goodwin, J. (1987). Correlates of menopausal hot flashes. Journal of Behavioral Medicine, 10(3), 277-285. doi:10.1016/0378-5122(88)90172-7

Gjelsvik, B., Rosvold, E. O., Straand, J., Dalen, I., \& Hunskaar, S. (2011). Symptom prevalence during menopause and factors associated with symptoms and menopausal age. Results from the Norwegian Hordaland Women's Cohort Study. Maturitas, 70(4), 383-390. doi:10.1016/j.maturitas.2011.09.011

Gold, E. B., Sternfeld, B., Kelsy, J. L., Brown, C., Mouton, C., Reame, N., ...Stellato, R. (2000). Relation of demographic and lifestyle factors to symptoms in a multi-racial/ethnic population of women 40-55 years of age. American Journal of Epidemiology, 152(5), 463-473. doi:10.1093/aje/152.5.463

Guthrie, J. R., Dennerstein, L., Taffe, J. R., \& Donnelly, V. (2003). Health care-seeking for menopausal problems. Climacteric, 6(2), 112-117. doi:10.1080/cmt.6.2.112.117

Haimov-Kochman, R., \& Hochner-Celnikier, D. (2005). Hot flashes revisited: Pharmacological and herbal options for hot flashes management. What does the evidence tell us? Acta Obstetricia et Gynecologica Scandinavica, 84(10), 927-979. doi:10.1111/j.0001-6349.2005.00769.x 
Pimenta, F., Maroco, J., Ramos, C. \& Leal, I. (2015). Hot Flushes and Night Sweats in Midlife: Why do Some Women Have Them and Others do Not?

Hardy, R., \& Kuh, D. (2002). Change in psychological and vasomotor symptom reporting during menopause. Social Science \& Medicine, 55(11), 1975-1988. doi:10.1016/S02779536(01)00326-4

Harlow, S. D., Gass, M., Hall, J. E., Lobo, R., Maki, P., Rebar, R. W., ...de Villiers, T. J. (2012). Executive summary of the Stages of Reproductive Aging Workshop + 10: Addressing the unfinished agenda of staging reproductive aging. Menopause, 19(4), 1-9. doi:10.1097/gme.0b013e31824d8f40

Huang, A. J., Grady, D., Jacoby, V. L., Blackwell, T. L., Bauer, D. C., \& Sawaya, G. F. (2008). Persistent hot flushes in older postmenopausal women. Archives of Internal Medicine, 168(8), 840-846. doi:10.1001/archinte.168.8.840

Hunter, M. S., \& Liao, K. L. (1995). A psychological analysis of menopausal hot flushes. British Journal of Clinical Psychology, 34(4), 589-599. doi:10.1111/j.2044-8260.1995.tb01493.x

Hunter, M. S., \& Mann, E. (2010). A cognitive model of menopausal hot flushes and night sweats. Journal of Psychosomatic Research, 69(5), 491-501. doi:10.1016/j.jpsychores.2010.04.005

Huntley, A. L., \& Ernst, E. (2003). A systematic review of herbal medicinal products for the treatment of menopausal symptoms. Menopause, 10(5), 465-476. doi:10.1097/01. GME.0000058147.24036.B0

Joffe, H., Hall, J. E., Soares, C. N., Hennen, J., Reilly, C. J., Carlson, K., \& Cohen, L. S. (2002). Vasomotor symptoms are associated with depression in perimenopausal women seeking primary care. Menopause, 9(6), 392-398 doi:10.1097/00042192-200211000-00003

Juang, K. D., Wang, S. J., Lu, S. R., Lee, S. J., \& Fuh, J. L. (2005). Hot flushes are associated with psychological symptoms of anxiety and depression in peri- and post- but not premenopausal women. Maturitas, 52(2), 119-126. doi:10.1016/j.maturitas.2005.01.005

Kandiah, J., \& Amend, V. (2010). An exploratory study on perceived relationship of alcohol, caffeine, and physical activity on hot flashes in menopausal women. Health, 2(9), 989-996. doi:10.4236/health.2010.29146

Kline, R. B. (2005). Principles and practices of structural equation modelling ( $\left.2^{\text {nd }} \mathrm{ed}\right)$. New York: The Guilford Press

Kravitz, H. M., Zhao, X., Bromberger, J. T., Gold, E. B., Hall, M. H., Matthews, K. A., \& Sowers, M. R. (2008). Sleep disturbance during the menopausal transition in a multi-ethnic community sample of women. Sleep, 31(7), 979-990.

Lermer, M., Morra, A., Moineddin, R., Manson, J., Blake, J., \& Tierney, M. (2011). Somatic and affective anxiety symptoms and menopausal hot flashes. Menopause, 18(2), 129-132. doi:10.1097/gme.0b013e3181ec58f8

Lovibond, P. F., \& Lovibond, S. H. (1995). The structure of negative emotional states: Comparison of the Depression Anxiety Stress Scales (DASS) with the Beck Depression and Anxiety Inventories. Behaviour Research and Therapy, 33(3), 335-343. doi:10.1016/0005-7967(94)00075-U

Maroco, J. (2010). Análise de equações estruturais: Fundamentos teóricos, software e aplicações. Pêro Pinheiro, Portugal: Report Number.

Melby, M. K., Lock, M., \& Kaufert, P. (2005). Culture and symptom reporting at menopause. Human Reproduction Update, 11(5), 495-512. doi:10.1093/humupd/dmi018

Murray, G. (2007). Diurnal mood variation in depression: A signal of disturbed circadian function? Journal of Affective Disorders, 102(1), 47-53. doi:10.1016/j.jad.2006.12.001
National Institutes of Health. (2005). National Institutes of Health State-of-the-Science Conference statement: Management of menopause-related symptoms. Annals of Internal Medicine, 142(12, Pt. 1), 1003.

Pais-Ribeiro, J. L., Honrado, A., \& Leal, I. (2004). Contribuição para o estudo da adaptação portuguesa das Escalas de Ansiedade, Depressão, e Stress (EADS) de 21 Itens de Lovibond e Lovibond. Psicologia, Saúde \& Doenças, 5(2), 229-239.

Pimenta, F., Leal, I., Maroco, J., \& Ramos, C. (2011). Perceived control, lifestyle, health, socio-demographic factors and menopause: Impact on hot flashes and night sweats. Maturitas, 69(4), 338-342. doi:10.1016/j.maturitas.2011.05.005

Pimenta, F., Leal, I., Maroco, J., \& Ramos, C. (2012). Menopause Symptoms' Severity Inventory (MSSI-38): Assessing symptoms' frequency and intensity. Climacteric, 15(2), 143-152. doi:10.3109/13697137.2011.590617

Progetto Menopausa Italia Study Group. (2005). Factors associated with climacteric symptoms in women around menopause attending menopause clinics in Italy. Maturitas, 52(3), 181189. doi:10.1016/j.maturitas.2005.01.008

Randolph, J. F., Jr., Sowers, M., Bondarenko, I., Gold, E. B., Greendale, G. A., Bromberger, J. T., ...Matthews, K. A. (2005). The relationship of longitudinal change in reproductive hormones and vasomotor symptoms during the menopausal transition. The Journal of Clinical Endocrinology and Metabolism, 90(11), 6106-6112. doi:10.1210/jc.2005-1374

Shaw, C. R. (1997). The perimenopausal hot flash: Epidemiology, physiology, and treatment. The Nurse Practitioner, 22(3), 55-69.

Sievert, L. L., Obermeyer, C. M., \& Price, K. (2006). Determinants of hot flashes and night sweats. Annals of Human Biology, 33(1), 4-16. doi:10.1080/03014460500421338

Stearns, V., Ullmer, L., Lopez, J. F., Smith, Y., Isaacs, C., \& Hayes, D. F. (2002). Hot flushes. Lancet, 360, 1851-1861. doi:10.1016/S0140-6736(02)11774-0

Thurston, R. C., \& Joffe, H. (2012). Vasomotor symptoms and menopause: Findings from the study of women's health across the nation. Obstectrics \& Gynecology Clinics of North America, 38(3), 489-501. doi:10.1016/j.ogc.2011.05.006

Weisberg, S. (1985). Applied linear regression ( $2^{\text {nd }}$ ed). New York: John, Wiley \& Son.

Whitcomb, B. W., Whiteman, M. K., Langenberg, P., Flaws, J. A., \& Romani, W. A. (2007). Physical activity and risk of hot flashes among women in midlife. Journal of Women's Health, 16(1), 124-133. doi:10.1089/jwh.2006.0046

Woods, N. F., Mariella, A., \& Mitchell, E. S. (2002). Patterns of depressed mood across the menopausal transition: Approaches to studying patterns in longitudinal data. Acta Obstetricia et Gynecologica Scandinavica, 81(7), 623-632. doi:10.1034/j.1600-0412.2002.810708.x 